\title{
The middle ground
}

Contemporary politics thrives on confrontation: in the United States, Britain, and much of the West issues are polarised into black and white alternatives. "Those who are not with me are against me" say our leaders, ignoring the possibility of conciliation and compromise.

In public life these attitudes are damaging; in science they are disastrous. How welcome, therefore, is Sir Douglas Black's deceptively short book An Anthology of False Antitheses. ${ }^{1}$ Like Tiresias, he has foresuffered all: he has been professor of medicine at Manchester, chief scientist at the Department of Health, and president of the Royal College of Physicians of London, and is uniquely qualified to comment on the way medical issues are currently debated.

Sir Douglas has collected a dozen or so examples of such arguments that are usually presented in either/or terms. Should medical research efforts be concentrated on applied rather than pure research? Is community care preferable to treatment in hospital? Should students be taught holistic rather than scientific medicine? Should resources be diverted from acute to chronic medicine?

None of these questions can be answered with a simple yes or no. For example, back in 1971 the Rothschild report was welcomed in Whitehall for its advocacy of research funding on a customer-contractor basis. "The customer says what he wants; the contractor does it (if he can); and the customer pays." Shortly after publication of the report Sir Douglas took up his post as chief scientist and found himself unable to work the system. At the heart of the problem was the lack of any purposeful dialogue between the research bodies and the bureaucrats. Civil servants and politicians seemed to believe that all they had to do was define a problem and then ask their scientists to solve it. President Nixon had set the fashion in the United States. With the dry humour that permeates the book Sir Douglas asks "Who other than the hero of Watergate would think of contracting for the cure of cancer or the prevention of cerebrovascular accidents?" In reality, as Sir Christopher Booth told his audience at the Royal Society last month, the most that can be asked of central government is that it should recognise the potential growth areas in science and encourage their development by providing research funds.

One by one, Sir Douglas demolishes a series of oversimplified analyses and asks his own awkward questions. On com- munity care, for example, he refers to plans by regional health authorities to move millions of pounds from acute hospital services to provide extra funds for elderly, mentally ill, and mentally handicapped patients in community rather than hospital care. He would not want to criticise a desire to do good or a desire to save money-but in a real world the question ought to be "What, within the limit of our resources, is most worth doing?"

So, given a decent standard of accommodation, what is actually likely to be achieved by deploying additional resources for the mentally handicapped once they have attained maturity? There may be good reasons for transferring patients from hospital to the community in order to avoid the dangers of institutionalisation-but it is not always apparent, as Sir Douglas observes, that resources apparently released in this way are actually deployed in strengthening community care. Furthermore, the care in the community, provided as it is likely to be very largely by individual families, is at an unknown social cost. He gently reminds the mandarins at the Department of Health and Social Security that "provided one goes underground the Elephant and Castle [where the DHSS has its headquarters in a decaying part of south east London] is quite a good vantage point for observing the social cost of a high discharge rate from mental hospitals."

At a time when planning and management are being advocated with ever greater enthusiasm as solutions for the problems of the NHS Sir Douglas's quiet warnings are very timely. "Those who profess great ends," he tells us, "can be both inwardly and visibly corrupted should they resort to evil means. Few of our actions are so simple and so devoid of consequence that we can be certain that the immediate wrong or even inconsiderate action will be amply redeemed by our noble purpose."

Doctors tempted to set the world to rights would do well to read the book; they might then, with Sir Douglas, see their priority as doing their best for their patients as individuals.

TONY SMITH

Deputy Editor,

$B M 7$

\footnotetext{
1 Black D. An anthology of false antitheses. Rock Carling Fellowship 1984. London: Nuffield Provincial Hospitals Trust, 1984

2 Anonymous. A framework for government research and development. London: HMSO, 1971 (Rothschild report.)
} 